\title{
A Review on Two Water Jugs Problem via an Algorithmic Approach Snehal Solanki ${ }^{1}$, Prem Parmar ${ }^{2}$, Parth Shukla ${ }^{3}$, Dhruvin Patel ${ }^{4}$, Mr.Nimit Modi $^{5}$, Dr.Sheshang Degadwala ${ }^{6}$ \\ ${ }^{1-4}$ U.G, Student, Computer Engineering, Sigma Institute of Engineering, Bakrol, Vadodara, Gujarat, India \\ ${ }^{5}$ Assistant Professor, Computer Engineering, Sigma Institute of Engineering, Bakrol, Vadodara, Gujarat, India \\ ${ }^{6}$ Head of Department, Computer Engineering, Sigma Institute of Engineering, Bakrol, Vadodara, Gujarat, India
}

\begin{abstract}
The water jugs problem is a well-known problem in recreational mathematics, problem-solving, artificial intelligence, computer programming and cognitive psychology. The methods of solutions are usually based on heuristics or search methods such as breadth first search (BFS) or depth first search (DFS), which could be time and memory consuming sometimes. The existing methods of solutions are often non-algorithmic in nature. In this paper, we present an arithmetic approach to solve this problem, which is simple and suitable for manual calculation or programming language implementation. Analysis of the solution steps involved and some illustrative examples are provided.
\end{abstract}

Keywords : Water jugs problem, Artificial Intelligence, Problem solving, Diophantine approach, Extended Euclidean approach.

\section{INTRODUCTION}

The Artificial Intelligence is the study of how to make computers to do things better than the human being. As the term says, here the water jug problem is wellknown problem in Artificial Intelligence [1], Computer Programming [2], Problem solving [3], Geometry [4], Recreational and discrete Mathematics $[5,6]$ and Psychology $[7,8,9]$.

You are at the side of a river. You have a 3 liter jug and a 5 liter jug. The jugs do not have marking to allow measuring smaller quantities. How can you use the jugs to measure 4 liters of water?

There are various methods to solve this problem, including Breadth First search [10], Depth First Search [11] and the Diophantine approach [12].

However each and every method has its own disadvantages that is in BFS the role is not get trapped by exploring a blind alley. In DFS, by chance we can assure that we will be getting the goal earlier and the memory space is less. In Diophantine approach the goal totally depends on the assumption that are made over the value of $\mathrm{X}$ and $\mathrm{Y}$.

In this paper a simple Arithmetic approach to solve the problem that was introduced. A novel feature of this approach is that one can deduce the total amount of water in jugs at each step by getting the value of $X$ and $\mathrm{Y}$ by using the backward approach. When these values are just substituted in the Extended Euclidean equation our goal will be reached. Due to its simplicity it is very suitable for manual calculation of the proving steps.

The whole paper is organized as follows. In section 2 the Arithmetic approach for solving the general two water jugs problem and it describe the mathematical background behind. In the third section, illustration of how to use the new approach with some examples is explained. Then in the final section some concluding remarks are explained.

\section{AN ARITHMETIC APPROACH TO THE WATER JUG PROBLEM}

A simple arithmetic approach to the general two water jugs problem was introduced which is applied 
to solve the problem below: Let $\mathrm{m}, \mathrm{n}$ be positive integers. You are at the side of a river. You have a $\mathrm{m}$ liter jug and a n-liter jug, where $0<\mathrm{m}<\mathrm{n}$. The jugs do not have markings to allow measuring smaller quantities. How can you use the jugs to measure $\mathrm{d}(<\mathrm{n})$ liters of water?

The Extended Euclidean algorithm is usually used simply to find the greatest common divisor of two integers. The standard Euclidean algorithm gives the greatest common divisor and nothing else.

However, if we keep track of a bit more information as we go through the algorithm, we can discover how to write the greatest common divisor as an integer linear combination of the two original numbers. In other words, we can find integers $s$ and $t$ such that $\operatorname{gcd}(a, b)=s a+t b$. From this equation we will be obtained only the GCD (m,n) but after getting it we have to follow a new procedure Back Substitution Method. The conclusion of this will be $m\left(x^{\prime}\right)+n\left(y^{\prime}\right)$ where $\mathrm{x}^{\prime}=$ number of moves to be carried out by $\mathrm{x}$ and $y^{\prime}=$ number of moves to be carried out by $y$.

As a reminder, here are the steps of the standard Euclidean algorithm to find the greatest common divisor of two positive integers a and $b$.

\section{Algorithm 2.1}

Input: The integers $\mathrm{m}, \mathrm{n}$ and $\mathrm{d}$, where $0<\mathrm{m}<\mathrm{n}$ and $\mathrm{d}<\mathrm{n}$.

Output: An integer sequence corresponding to a feasible solution obtained by filling the $\mathrm{m}$-litre jug and n-litre jug.

Procedure: 1 . Set the value of the variable $\mathrm{c}$ to the larger of the two values $a$ and $b$ and set $d$ to the smaller of $a$ and $b$. 2. Find the quotient and the remainder when $\mathrm{c}$ is divided by $\mathrm{d}$. Call the quotient $\mathrm{q}$ and the remainder $r$. Use the division algorithm and expressions for previous remainders to write an expression for $r$ in terms of $a$ and $b$. 3. If $r=0$, then $\operatorname{gcd}(a, b)=d$. The expression for the previous value of $r$ gives an expression for $\operatorname{gcd}(a, b)$ in terms of $a$ and $b$. Stop. 4. Otherwise, use the current values of $d$ and $r$ as the new values of $\mathrm{c}$ and $\mathrm{d}$, respectively, and go back to step 2. In this algorithm, we will be getting the GCD $(\mathrm{m}, \mathrm{n})$. Using the algorithm 2.1 we obtain the integer sequence.

Finding out the GCD is the first process and after that we have to use the Back-substitution method.

Algorithm 2.2:

1. In each of the equations, subtract the product term from the number on the left-hand-side and set it equal remainder on the right-hand-side. 2. Backwards: Write down the _last_flipped equation, the one with the gcd in it, and then alternate it by subbing the smallest underlined term and collecting terms the remaining terms.

From this algorithm, the number of subtractions and additions involved will provide a solution to the problem. By using this Extended Euclidean Approach and the Backward Substitution method actual pouring sequence can be determined easily by looking at the numbers appeared in the integer sequence obtained.

\section{EXAMPLE}

We are given 2 jugs, a 4 liter one and a 3- liter one. Neither has any measuring markers on it. There is a pump that can be used to fill the jugs with water. How can we get exactly 2 liters of water in to the 4 -liter jugs?

\section{Solution:-}

The state space for this problem can be defined as

$$
\{(i, j) i=0,1,2,3,4 j=0,1,2,3\}
$$

'i' represents the number of liters of water in the 4liter jug and ' $j$ ' represents the number of liters of water in the 3 -liter jug. The initial state is $(0,0)$ that is no water on each jug. The goal state is to get $(2, n)$ for any value of ' $n$ '.

To solve this we have to make some assumptions not mentioned in the problem. They are

1. We can fill a jug from the pump.

2. we can pour water out of a jug to the ground. 
3. We can pour water from one jug to another.

4. There is no measuring device available.

The various operators (Production Rules) that are available to solve this problem may be stated as given in the following figure .

\begin{tabular}{|c|c|c|}
\hline $\begin{array}{c}\text { Rule } \\
\text { No }\end{array}$ & Production Rule & Action \\
\hline 1 & $\begin{array}{l}(i, j)-(4, j) \\
\text { if } i<4 .\end{array}$ & Fill the 4-liter jug, if 4-liter jug is not full. \\
\hline 2 & $\begin{array}{l}(i, j)-(i, 3) \\
\text { if } j<3 .\end{array}$ & Fill the 3 -liter jug, if 3 -liter jug is not full. \\
\hline 3 & $\begin{array}{l}(i, j)-(i-s, j) \\
\text { if } i>0 .\end{array}$ & $\begin{array}{l}\text { Pour some water our of the 4-liter jug, if } \\
\text { 4-liter jug is not empty. }\end{array}$ \\
\hline 4 & $\begin{array}{l}(i, j)-(i, j-s) \\
\text { if } j>0 .\end{array}$ & $\begin{array}{l}\text { Pour some water out of the 3-liter jug, if } \\
\text { 3-liter jug is not empty. }\end{array}$ \\
\hline 5 & $\begin{array}{l}(i, j)-(0, j) \\
\text { if } i>0 .\end{array}$ & $\begin{array}{l}\text { Empty the 4-liter jug on the ground, if } 4 \text {-liter } \\
\text { jug is not empty. }\end{array}$ \\
\hline 6 & $\begin{array}{l}(i, j)-(i, 0) \\
\text { if } j>0 .\end{array}$ & $\begin{array}{l}\text { Empty the 3-liter jug on the ground, if 3-liter } \\
\text { jug is not empty. }\end{array}$ \\
\hline 7 & $\begin{array}{l}(i, j) \underset{(4, j-(4-i))}{(i+j)>=4 \& j>0 .} \\
\text { if }(i+j)\end{array}$ & $\begin{array}{l}\text { Pour water from the } 30 \text {-liter jug into the } \\
4 \text {-liter jug until the } 4 \text { liter jug is full, if the } \\
\text { combined content is }>=4 \text { and } 3 \text {-liter jug is } \\
\text { not empty. }\end{array}$ \\
\hline 8 & $\begin{array}{l}(i, j)=(i,(3-j), 3) \\
\text { if }(i+j)>=3 \& \text { \& } i>0 .\end{array}$ & $\begin{array}{l}\text { Pour water from the } 4 \text {-liter the into the } 3 \\
\text { liter jug until the } 3 \text {-liter jug is full if the } \\
\text { combined content is }>=3 \text { and } 4 \text {-liter jug is } \\
\text { not empty. }\end{array}$ \\
\hline 9 & $\begin{array}{l}(i, j)-(i+j, 0) \\
\text { if }(i+j)<=4 \text { and } j>0 .\end{array}$ & $\begin{array}{l}\text { Pour all the water from the } 3 \text {-liter jug into } \\
\text { the } 4 \text {-liter jug if the jug, combined content is } \\
<=4 \text { and } 3 \text {-liter jug is not empty. }\end{array}$ \\
\hline 10 & $\begin{array}{l}(i, j) \\
\text { if } i+j)<=3 \text { and } i>0\end{array}$ & $\begin{array}{l}\text { Pour all the water from the } 4 \text {-liter jug into } \\
\text { the3-liter jug, if the combined content is } \\
<=3 \text { and 4-liter jug is not empty }\end{array}$ \\
\hline
\end{tabular}

For the water jug problem, there are several sequence of operators that will solve the problem. let us see of them.

SOLUTION 1;-

\begin{tabular}{|c|c|c|}
\hline $\begin{array}{c}\text { Liters in the 4-liter } \\
\text { jug }\end{array}$ & $\begin{array}{c}\text { Liters in the 3-liter } \\
\text { jug }\end{array}$ & Rule applied \\
\hline 0 & 0 & \\
\hline 4 & 0 & 1 \\
\hline 1 & 3 & 8 \\
\hline 1 & 0 & 6 \\
\hline 0 & 1 & 10 \\
\hline 4 & 1 & 1 \\
\hline 2 & 3 & 8 \\
\hline
\end{tabular}

Solution 2:-

\begin{tabular}{|c|c|c|}
\hline $\begin{array}{c}\text { Liters in the 4-liter } \\
\text { jug }\end{array}$ & $\begin{array}{c}\text { Liters in the 3-liter } \\
\text { jug }\end{array}$ & Rule applied \\
\hline 0 & 0 & \\
\hline 0 & 3 & 2 \\
\hline 3 & 0 & 9 \\
\hline 3 & 3 & 2 \\
\hline 4 & 2 & 7 \\
\hline 0 & 2 & 5 \\
\hline 2 & 0 & 9 \\
\hline
\end{tabular}

Solution 3:-

\begin{tabular}{|c|c|c|}
\hline Liters in the 4-liter jug & $\begin{array}{c}\text { Liters in the 3-liter } \\
\text { jug }\end{array}$ & Rule applied \\
\hline 0 & 0 & \\
\hline 4 & 0 & 1 \\
\hline 1 & 3 & 8 \\
\hline 0 & 3 & 5 \\
\hline 3 & 0 & 9 \\
\hline 3 & 3 & 2 \\
\hline 4 & 2 & 7 \\
\hline 0 & 2 & 5 \\
\hline 2 & 0 & 9 \\
\hline
\end{tabular}

Figures gives comparative study of the above 3 different solutions.

Fig :- comparison of 3 solutions.

We see that, when there is no limit for water prevails then solution is the most efficient. When water is limited then Solution 2 is the best suited. In no way, solution 3 is good, Because it it requires $\mathbf{8}$ steps to solution and wastes 5 liters of water. 


\section{CONCLUSION}

In Breadth First Search all nodes has to be evaluated and instead of finding a single node we will be forced to find many answers and it is waste of time. It is its main disadvantages.

In Depth First Search, this method single and unfruitful path is being carried out for a very long time and longer path never explored until the entire shorter one has been examined.

So we choose Diophantine equation here the values for both $\mathrm{x}$ and $\mathrm{y}$ is just assumption so that we have to work from the first and by chance if sometimes the equation satisfies means then we will consider it. But only by chance we will work on it.

The new approach the Extended Euclidean Approach that is being founded in this paper has many and more number of advantages. The first and the foremost one is we don't want to do any guess, by having the input itself we are able to get the output. By using the Extended Euclidean Approach, we are able to get the appropriate result with less work, complexity and memory. We can assure that the answer what is found out is efficient and effective.

\section{REFERENCE}

[1] S. Abu Naser, "Developing visualization tool for the teaching AI searching algorithms," Information Technology Journal, 7(2), 2008, pp. 350-355.

[2] C. J. McDiarmid and J. R. Alfonsin, "Sharing jugs of wine," Discrete Mathematics, vol. 125, 1994 pp. 279-287.

[3] G. Polya, How to Solve It. NJ: Princeton University Press, 1945.

[4] H.S.M.Coxeter and S.L.Greitzer, Geometry Revisited. Washington D.C.: The Mathematical Association of America, 1967.

[5] B. Harvey, Computer Science Logo Style: Symbolic Computing (Vol. I), MA: MIT, 1997.

[6] M. K. Colvin, K. Dunbar and J. Grafman, "The effects of frontal lobe lesions on goal achievement in the water jug task," Journal of Cognitive Neuroscience, 13(8), 2001, pp. 11291147.

[7] D. M. Burdon, Elementary Number Theory, 5th edition, NY: McGraw-Hill, 2002.

[8] F. Leon, M. H. Zaharia, and D. Galea, "A heuristic for solving the generalized water jugs problem," Bulletin of the Polytechnic Institute of Iasi, fasc. 1-4, 2005, pp. 95-102.

[9] S. L. Beilock and M.S. DeCaro, "From poor performance to success under stress: working memory, strategy selection and mathematical problem solving under pressure," Journal of Experimental Psychology, 33(6), 2007, pp. 983998.

[10] H. P. Carder, S. J. Handley and T. J. Perfect, "Counterintuitive and alternative moves choice in the water jug tasks," Brain and Cognition, vol. 66, 2008, pp. 11-20. 